Journal of Humanities, Social and Management Sciences (JHSMS) eISSN: 2788-4791 (online) https://doi.org/10.47264/idea.jhsms/3.1.2 Vol. 3, No. 1 (January-June 2022), 16-25

\title{
Role of news media in the peacebuilding process
}

\author{
Muhammad Umair Chaudhary*1 | Sobia Usman ${ }^{2}$ | Usman Farooq ${ }^{3}$ \\ 1. Department of Mass Communication, Virtual University, Lahore, Pakistan. \\ 2. Faculty of Fashion and Design, Indus University Karachi, Karachi, Pakistan. \\ 3. Department of Media Studies, The Islamia University of Bahawalpur, Pakistan.
}

*Corresponding Author Emails: umair.chaudhary@vu.edu.pk | thechaudhary@ hotmail.com

Received: October 13, $2021 \quad$ Accepted: January 02, $2022 \quad$ Published: January 19, 2022

\begin{abstract}
This research study attempts to inspect the job of the news media in a continuous peace process. This study also clarifies the peace contemplates and the current media rehearses at the local, national and international levels. Media networks are quickly reworking the conventional standards and conventions of war and struggle to announce. The qualitative descriptive research methodology has been used for this paper. This research has been conducted on the case study research because it involves a deep dive and thorough understanding of the data collection methods and inferring the data. Various research studies conducted during the period from 20002021 have been examined and selected for the present study. According to the research studies, media networks are quickly reworking the conventional standards and conventions of war and struggle to announce. This article supports the claim that researchers may promote social order and network peace-building efforts with the use of new media technologies. Their compositions in alternative media may offer a compelling form of commitment between the audiences and people affected in the area of a terrible battle.
\end{abstract}

Keywords: media, news media, media networks, media technology, peace, peace process, social order, peacebuilding.

How to Cite:

Chaudhry, M. U., Usman, S., \& Farooq, U. (2022). Role of news media in the peacebuilding process. Journal of Humanities, Social and Management Sciences (JHSMS), 3(1), 16-25. https://doi.org/10.47264/idea.jhsms/3.1.2

Publisher's Note:

IDEA PUBLISHERS (IDEA Publications Group) stands neutral regarding jurisdictional claims in the published maps and institutional affiliations.

Copyright: ( $\odot 2022$ The Author(s), published by IDEA PUBLISHERS (IDEA Publications Group).

Licensing: This is an Open Access article published under the Creative Commons AttributionNonCommercial 4.0 International License (http://creativecommons.org/licenses/by-nc/4.0/) 


\section{Introduction}

Peace in a society may be achieved by ethical reporting in the media. There are negative consequences to biases in journalism that favour a specific political party, people, or even a social topic, such as polarizing the population. There is a rise in animosity and disdain for others' points of view when the media presents a skewed perspective to its audience. When it comes to eradicating national intolerance and prejudice, the media plays a particularly important role in emerging nations. Furthermore, the media, as a means of communication and representation, may play a function as a virtual mentor, helping to discourage deviant inclinations that are destructive to the societal stability by reinforcing the normative ideals (Riaz, 2017).

Media has a wide chance to scatter data and it has an enormous ability to encroach on open insight about any nearby, public, and global occasion in peace (Ishaq et al., 2018). The prospects were accessible for the media to assume a surer part in struggle circumstances and assist with building peace in social orders in the new age media. It contends for the need to have a 'more extensive model of media' to accomplish that objective and talks about its suggestions for the people who practice the calling in the light of existing substitute models. It presumes that any media model that can give 'a characteristic fit to the $21^{\text {st }}$ Century should have the adaptability and innovativeness to utilize the mechanical headways that portray the time of new media (Aslam, 2016; Ashraf, 2021).

The media is alluding to various mediums or directs utilized in a coordinated way to impart data to gatherings of individuals as a support of people in general. The media is made out of mass correspondence communicated through a medium (channel) that all the while arrives at countless individuals. The term explicitly electronic media states transmission or capacity media that take advantage of electronic innovation. TV, radio, web, fax, portable, and some other medium that requires power or advanced encoding of data are instances of electronic media (Ali et al., 2021). The setup media is demonstrating to address specific vested parties the build-up media advances the interests of select vested parties accordingly at last present issues such that requests to those of specific vested parties. The news features from the setup Cyprus media as proof of the job that news media play in interethnic relations, struggle, and peacebuilding (Savrum \& Miller, 2015; Malik \& Jan, 2021).

This article breaks down the degree to which media addresses a non-state actor that is inclining the way intra-state and highway issues are seen. The accentuation is on whether or not the setup news media's depiction of the notorious other is impacting the peace-building process decidedly. As such, this article examines the degree to which the setup news media is affecting (emphatically) how people see, feel about, and act toward different identities, societies, as well as ethnic gatherings.

It ought to be clear, nonetheless, to even the most easy-going onlookers that the news media assume a basic part in endeavours to bring down threats among bad guys. The general population, given the circumstances, gets all of its data about 'the opposite side' from the media. An effective peace process requires persistence in the efforts, and the news media requires promptness. Peace is probably going to create inside a quiet climate and the media have a fanatical interest in the dangers and the brutality. Peacebuilding is a perplexing interaction, and the news media manage straightforward occasions. The progress towards peace 
needs something like a negligible comprehension of the requirements of the opposite side, yet the news media support ethnocentrism and antagonism towards enemies (Wolfsfeld et al., 2008; Ryan, 2011; Jan et al., 2021).

The research questions of the current research study are:

- How does the media play its role in the peacebuilding process? and

- In what ways does media play actively in the peacebuilding process?

The objectives of the study are:

- To know and analyse the role of news media in the peacebuilding process; and

- To know the impact of news media in the peacebuilding process.

\section{Literature review}

Wolfsfeld (1997) describes that the review comprised of the news media are bound to assume the part of "loyal workers" by underlining the official edges and either overlooking or undermining the challengers. The point of exploration in this space is to all the more likely see how and when the news media assume an autonomous part in coverage of the governmental issues at national and international levels. Inspecting an assortment of issues and cases works with the advancement of a thorough and dynamic model. Indeed, even the most relaxed spectator cannot neglect to be dazzled with the capacity of the news media to serve either a productive job in the advancement of peace.

López and Sabucedo (2007) describe that additionally, the impact of media will be significantly more significant in emergency and political struggle times since people require clarification or which means for all that happens at unprecedented occasions. Thus, they go to broad communications for a reply or to approve their perspectives. Consequently, the level of impact of the media might be expanded under such conditions. The broad communications impact the formation of those methods of review and sorting out the real world.

Hanitzsch (2007) believes that the extreme cases have been employed to expound on the war journalism, which is not suitable strategy. This approach sometimes exaggerates how influential mass media can be in swaying the policymakers and the authorities and undermines the importance of the viewers and the readers as "critical consumers," as the researcher continues to stress.

According to Bratic (2008) utilizing peace situated media in struggle, conditions have been practically speaking throughout the previous 15 years or somewhere in the vicinity, and an assortment of the undertakings exist in the field. A missing part is a complete investigation of the multitude of tasks that would move towards the overall thought instead of a solitary provincial application.

A broad arrangement of peace situated media projects are following:

- An ongoing history or presence of furnished struggle/brutality in the locale-this qualification is made to separate between media in struggle regions and media projects 
pursuing the democratization of states on the move (for example the Czech and Slovak Republics).

- Post-Cold War just over the most recent 20 years have broad communications hardware and innovation become reasonable and compact, permitting the foundation of new media sources as a quick reaction to a contention.

- The involvement of an outsider the presence of an outsider is the thing that recognizes peace situated media from modern publicity (for example American media relations in Iraq).

- Intentional reason to zero in just on explicit projects pointed toward changing struggle, the review rejects tasks and media channels that are as of now working and delivering media content in the district of contention yet are not doing anything remarkable in light of the rough clash.

Rawat (2014) states that the media has a vital role to play in fostering world peace. Print media, electronic media, and digital media provide wattage to that news which is useful for fostering peace. Various religious, social, educational, national, and international organizations hold nonviolent conferences, seminars, symposiums, etc., and other types of events, all of which are covered by the media. As a result, the media may be credited for helping to spread messages of harmony, love, joy, and serenity.

Savrum and Miller (2015) portray that the degree to which the set-up news media can channel data purposefully similarly as with promulgation. "Promulgation is the conscious and orderly endeavour to shape discernments, control insights, and direct conduct to accomplish a reaction that encourages the ideal plan of the disseminator". The staggering effect of the media content investigation is a suitable instrument for exploring the job that the media play in impacting worldwide issues at multi-levels. A pertinent technique for investigating the job of media in highway relations since it uncovers the degree to which the media can outline issues, build up impressions, and set plans in manners that fundamentally affect struggle, security, and endeavours toward peacebuilding.

According to Riaz (2017), the existence of a peaceful and harmonious society is essential to the survival and advancement of civilization. A world without socio-polictical harmony and peace will inevitably come to a standstill, bringing about a return to the dark ages when the mighty preyed on the weak. The welcoming signals of wealth and cooperative humanity, peace, and agreement serves as a foundation for the full development and the recognition of the human potential, a boost to the global economy, and a guarantee for the long-term survival of the human race.

De Coning (2018) states that a real shift is taking place in the work of promoting peace across the world. New methods to peacebuilding are developing as liberal idealism fades away. According to the researcher, a new method to peacebuilding called "adaptive peacebuilding" has been identified, named, and the potential benefits of this approach are explored. As a result, the UN's evolving notion of maintaining peace may be more informed when it comes to implementing it. In contrast to the neo-liberal paradigm that has dominated peacebuilding for the last three decades, there offers an alternative. As part of an inductive methodology, peacebuilders work closely with communities and individuals impacted by war to preserve peace via systematic processes of learning and adapting. The peacebuilding that takes an 
adaptable approach relies on institutions at all levels, not only at the national or international level, to be resilient in the face of adversity.

Graciyal and Viswam (2018) state that all corporations, governments, non-profit organizations, political interest groups, and most importantly, people interact and cooperate in real-time through the growth of technology and computer networks in an increasingly linked world. Because of the ease with which information can now be transferred, people are making use of these avenues to disseminate information, which in turn leads to tensions and wars. For local and worldwide audiences, well-developed media systems with educated journalists provide a lifeline to the outside world, especially during times of turmoil. Social media's role in conflict and its capacity to mediate peace isn't being effectively addressed, despite its importance. social media is the most popular and sensitive channel for fostering peace since it provides safety and human security as well as social and moral integrity.

Ishaq et al. (2018) state that different multinational media corporations portrayed the story of war differently. Protests, annihilations, depressions, and deaths of civilians were more prevalent in Arab online media clusters. On the other side, European and American media focused on elite orientation, technical dominance; supersonic missiles, the newest armaments, drones, etc., and typically ignored human misery and anti-war rallies.

Lanz and Eleiba (2018) describes that as conflict parties and mediators alike increasingly turn to technology for a variety of objectives, the field of peace mediation is changing rapidly. Although this tendency is expected to continue, mediators have not been well trained for the influence of new technology on peace mediation (Legatis, 2015).

According to Mbabazi et al. (2020) gendered peacebuilding is necessary because it adds fresh subtleties and viewpoints to the process of conflict resolution and peacebuilding. Men's militarization of peace processes and policies is countered by a process of gendered peacebuilding. Additionally, it aids in the development of peacebuilding procedures that are not based on gender stereotypes. A gendered peacebuilding process goes beyond the fundamentalist interpretation of reality that is common in the field of conflict resolution. Moreover, the inclusion of both masculine and feminine views in peacebuilding processes produces a paradigm change in the usage of languages and techniques. The gendered approaches to peacebuilding help achieve a peaceful, inclusive, and long-lasting resolution to conflict because they rely on the unique perspectives of both men and women when addressing global concerns.

McKell (2020) argued that Civil Society Organizations (CSOs) utilize media to help them achieve their objectives. When it comes to CSOs working to promote peace in Bosnia and Herzegovina $(\mathrm{BiH})$, it has become clear that using a variety of communication and media methods is both essential and effective. As a post-conflict society where peacebuilding and reconciliation efforts are not only ongoing but becoming more vital. The media is a vital aspect of contemporary society, but the ability of the media to be exploited and misused is now universally acknowledged, and this is especially true in Bosnia and Herzegovina. Although they do not have the same way as the mainstream media, yet any attempt is a good thing for bringing improvements. As long as the CSOs continue to generate the high-quality journalism, the media environment will benefit from the addition of more diverse perspectives and a place for the peacebuilding in the media (Curtis, 2000). 
According to Ali et al. (2021) media has arisen as a solid medium informing general assessment and discernment, and for the advancement of peacebuilding drives. At the same time, media can progress or limit the effect of unsafe images in changing social connections. This inclination makes an intrinsic clash in the media's capacity to help accomplish or to frustrate tranquil objectives. Media features programs and reports explicit interest of changing mentalities and practices from savagery and leads towards peace. Towards peace advancement a far and wide selection of stages and tasks focus to shape connections through the lines of contention, establishing a base for open correspondence.

Kabaji (2021) explains that the traditional African media in promoting peace and harmony in African communities and families. In today's world, folk media is a useful way of communication and peacebuilding. Folk media, among other things, enables youngsters to find purpose in their lives and ties them to their cultural traditions. It also instils principles of peace, solidarity, and humanistic coexistence among students.

Devine et al. (2021) discuss that during the post-violence phase of a conflict, cultural events may play a peacebuilding function. Authors examined the city's Fleadh Cheoil (2013) event as an example of a controversial topic in Northern Ireland and concluded that it satisfied three of the seven peacebuilding tasks identified by Paffenholz and Spurk: Societal cohesiveness, ingroup socialization, and mediation/facilitation. It seems that the event helped to bring about a good shift by creating "bridges" and fostering mutual trust and respect among the many communities involved. However, the event was organized and managed to ensure that it was accessible to all participants. Taking risks, showing compassion, and being prepared to compromise were all qualities that were needed in this situation. As a result of this, crosscommunity exchanges have a far-reaching impact on society. Culture events may play a part in peacebuilding, but they are not a cure for sectarianism, bigotry, or violence Trust, tolerance, and understanding are important building blocks for peaceful coexistence amongst people in divided communities.

\section{Research methodology}

This section portrays the system of inquiry, which includes a contextual study of media as a peace expert. The research examines activities for establishing useful links between media and peacebuilding by using essential concepts in locating hypotheses (Afaghani, 2011). Qualitative research has been used for this paper. Investigate the normal spaces of shared comprehension for peace talks and exchange to determine the issue. Investigate the foundation, inconspicuous financial guides, provincial control, and impending meanings of it. Spotlights on the fundamental entertainers liable for the entire circumstance. Examine the circumstance without marking anybody unrivalled or sub-par (Ishaq et al., 2018).

This research has been conducted on the case study research because it involves a deep dive and thorough understanding of the data collection methods and inferring the data. This research study will help to identify the vital role of media plays as an agent of peacebuilding in our society. The sample size of the present study is 12 research papers that have been published between 2000-2021. The information collected from these research papers that were perceived as a part of the general opinions eradicated from the enlightening record. Regardless, the data quality and several types of research suggest this data give a strong reason from which to examine plans in responses to media channels choice. 
The data used for the assessment was aggregated using a review structure by using the compartmentalizing of the data collected. The study is the most suitable device for this assessment because the safest ways of managing gather qualitative information. It is convenient and simple to set up outcomes. According to the exploration point, for the arrangement of data use purposeful sampling. In this assessment, the researcher portrayed the specific objective group that explains the procedures and characteristics. The objective of using this purposeful investigating methodology is to lead the responsive investigation.

\section{Analysis and discussion}

In the wake of analysing the literature, the researchers dissected that the primary ramifications for media are to make 'peace' news esteem. Peace is a significant trait as it gets 'the upsides of straightforwardness and obligation. Corresponding to the news media, "the idea of "peace" has still not been enough conceptualized'. Corresponding to the news media, "the idea of "peace" has still not been satisfactorily conceptualized'. Numerous researchers have contended for ascribing media with the 'esteem unequivocal methodology' of peace however with the media obligation to express current realities and an unmistakable description of how these realities are met. This would loan it the authenticity to be incorporated inside the worldview of the expert media.

The new worldview of information esteems permits peace story or occasion to turn into the 'news' when a conflict turns into daily practice, awful yet tedious, dull, evidently exhausting. Notwithstanding, identified with making 'peace' news esteem is the precarious matter of characterizing the term "peace" itself an issue that leads individuals to mistake it for 'activism' and 'support'. An effective peace process requires persistence and the news media request instantaneousness. Peace is probably going to create inside a quiet climate and the media have an over-the-top interest in dangers and brutality. Peacebuilding is an intricate cycle, and the news media manage basic occasions.

In the wake of analysing the literature, the researcher scrutinized that the primary ramifications for media are to make "peace" news esteem. Peace is a significant trait as it gets "the upsides of straightforwardness and obligation". Corresponding to the news media, "the idea of "peace" has still not been enough conceptualized'. Corresponding to the news media, 'the idea of "peace" has still not been satisfactorily conceptualized'. Numerous researchers have contended for ascribing media with the 'esteem unequivocal methodology' of peace however with the media obligation to express current realities and an unmistakable description of how these realities are met. This would loan it the authenticity to be incorporated inside the worldview of expert media. The new worldview of information esteems permits peace story or occasion to turn into the 'news' when a conflict turns into daily practice, awful yet tedious, dull, evidently exhausting. Notwithstanding, identified with making 'peace' news esteem is the precarious matter of characterizing the term "peace" itself an issue that leads individuals to mistake it for 'activism' and 'support'.

An effective peace process requires persistence and the news media request instantaneousness. Peace is probably going to create inside a quiet climate and the media have an over-the-top interest in dangers and brutality. Peacebuilding is an intricate cycle, and the news media manage basic occasions. The media have become a social arena in which force is a viable option. For the media and its followers, a societal duty is to take a constructive role in resolving 
conflicts and pointing toward peace. Peace is in this manner talked about here as one of the substitutes and more extensive models for media in the new age that can assist with boosting the job of media in peacebuilding and struggle decrease.

The other three are the substitute media and correspondence freedoms development and basic liberties news coverage. They are then examined in the light of one another alongside their suggestions for media as a calling. The zeroed in on referenced articles has been lessening the level and measure of disdain messages instigating viciousness during the contention would essentially limit the adverse consequence of the media on the crowd. Peace situated diversion, newscasting, and some other peace media projects would be best in a climate where sentimentalists disdain media don't occupy the public's consideration.

\section{Conclusion}

The goal of this research was to understand the role of the media as a peacemaker in our society. The watcher aimlessly trusts the media confidence and media with the assistance of genuine substance satisfy this guarantee. It was contended that in the $21^{\text {st }}$ Century, the media utilize distinctive new methodologies and innovations to get the genuine story for the news. The media pass on the genuine storyline to their crowd in a state of contentions and war. The media likewise assume the fundamental part to determine the issue with the assistance of correspondence at nearby, public, and global levels. Peace venture from media establishes a positive climate, where circumstances that can without much of a stretch be sensible with various peace strategies. With the rise of social media and greater access to the internet, some aspects of peace journalism are already in use. These include making conflicts transparent, giving voice to all parties, and humanization of all sides, exposing untruths on all sides, and focusing on suffering all over including on women, the elderly, children, and those who have no one to speak for them. Journalists and their audiences may get a better knowledge of conflict and peaceful resolutions by using the peace journalism paradigm.

\section{References}

Afaghani, R. (2011). News media and peacebuilding: Uncovering opportunities that can facilitate cooperation .Doctoral Dissertation, George Mason University. http://mars.gmu.edu/xmlui/handle/1920/6334?show=full

Ali, M., Elahi, N., Shah, I., \& Alam, A. (2020). Analyzing the potential role of media in representing peace and development initiatives in post-conflict Swat. ASIAN Journal of International Peace \& Security (AJIPS), 4(2), 89-102. http://ajips.fairlips.org/index.php/ajips/article/view/2020-vol-4-analyzing-thepotential-role-of-media

Aslam, R. (2016). Building peace through journalism in the social/alternate media. Media and Communication, 4(1), 63-79. https://doi.org/10.17645/mac.v4i1.371

Ashraf, S. I. (2021). The fixer on the Pak-Afghan frontier: A de-skilled local labour in the global media. Liberal Arts and Social Sciences International Journal (LASSIJ), 5(2), 1-16. https://doi.org/10.47264/idea.lassij/5.2.1

Bratic, V. (2008). Examining peace-oriented media in areas of violent conflict. International Communication Gazette, 70(6),

https://doi.org/10.1177/1748048508096397

487-503. 
Curtis, D. E. (2000). Broadcasting peace: an analysis of local media post-conflict peacebuilding projects in Rwanda and Bosnia. Canadian Journal of Development Studies/Revue canadienne d'études du développement, 21(1), 141-166. https://doi.org/10.1080/02255189.2000.9669886

De Coning, C. (2018). Adaptive peacebuilding. International Affairs, 94(2), 301-317. https://www.chathamhouse.org/sites/default/files/images/ia/INTA94_2_05_DeConi ng\%20.pdf

Devine, A., Quinn, B., \& Devine, F. (2021). Reaching across the divide-the role of cultural events in peacebuilding. Event Management. https://doi.org/10.3727/152599519X15506259856552

Graciyal, D. G., \& Viswam, D. (2018). Social media and peace building in Indian politics. Research Journal of Humanities and Social Sciences, 9(1), 135-138. https://rjhssonline.com/AbstractView.aspx?PID=2018-9-1-24

Hanitzsch, T. (2007). Situating peace journalism in journalism studies: A critical appraisal. Conflict and Communication Online, 6(2), 1-9. https://regeneronline.de/journalcco/2007_2/pdf/hanitzsch.pdf

Ishaq, N., Saleem, N., \& Mian, H. A. (2018). Media an agent of peace or war? A study of The Economist, The Herald and Time during American armed operations in Pakistan. Pakistan Vision, 19(1), 76-93. http://pu.edu.pk/images/journal/studies/PDF-FILES/Article_5_2018 07_12.pdf

Jan, F., Ashraf, S. I., \& Shah, S. F. A. (2021). Khamosh Pani: Partition trauma, gender violence, and religious extremism in Pakistan. Liberal Arts and Social Sciences International Journal (LASSIJ), 5(1), 16-27. https://doi.org/10.47264/idea.lassij/5.1.2

Kabaji, E. (2021). The role of folk media in peacebuilding: Folk storytelling tradition as a site for peaceful negotiation for gender harmony in African families. In Media, Conflict, and Peacebuilding in Africa (pp. 70-83). Routledge. https://doi.org/10.4324/9780429344862

Lanz, D., \& Eleiba, A. (2018). The good, the bad and the ugly: Social Media and peace mediation. Swiss Peace Policy Brief. https://www.swisspeace.ch/publications/policybriefs/the-good-the-bad-and-the-ugly-social-media-and-peace-mediation-3

Legatis, R. (2015). Media-related peacebuilding in processes of conflict transformation. Berghof Foundation Operations $\mathrm{GmbH}$.

López, W. L., \& Sabucedo, J. M. (2007). Culture of peace and mass media. European Psychologist, 12(2), 147-155. https://doi.org/10.1027/1016-9040.12.2.147

Malik, T., \& Jan, F. (2021). Foucauldian biopower, homo sacer and resistance under the Taliban rule in Afghanistan. Liberal Arts and Social Sciences International Journal (LASSIJ), 5(1), 582-596. https://doi.org/10.47264/idea.lassij/5.1.38

Mbabazi, V., Naiga, R., \& Helen, N. N. (2020). Towards gendered peacebuilding processes for sustainable peace. Jadavpur Journal of International Relations, 24(2), 133-151. https://doi.org/10.1177/0973598419896441

McKell, K. E. (2020). How Civil Society Organizations (CSOs) use media for peacebuilding in post-conflict societies (No. GRI-2020-27361). Aristotle University of Thessaloniki. http://ikee.lib.auth.gr/record/319287/files/GRI-2020-27361.pdf

Rawat, R. K. (2014). Role of media promoting peace in global political contexts. International Journal of Education and Science Research, 1(4), 786-790. http://www.ijesrr.org/publication/9/IJESRR\%20V-1-4-2.pdf

Riaz, S. (2017). Role of media in promoting peace and harmony. ISSRA Papers, 9(II). https://www.prdb.pk/article/role-of-media-in-promoting-peace-and-harmony-164 
M. U. Chaudhry, S. Usman \& U. Farooq

Ryan, L. C. P. (2011). The role of local media in peacebuilding in Nepal. Master's thesis submitted to The University of North Carolina at Chapel Hill.

Savrum, M. Y., \& Miller, L. (2015). The role of the media in conflict, peace building and international relations. International Journal on World Peace, 32(4), 13-34. https://link.gale.com/apps/doc/A436695027/AONE?u=edgewood_oscar\&sid=googl eScholar\&xid $=84 \mathrm{c} 454 \mathrm{c} 1$

Wolfsfeld, G. (1997). Promoting peace through the news media: Some initial lessons from the Oslo peace process. Harvard International Journal of Press/Politics, 2(4), 52-70. https://doi.org/10.1177/1081180X97002004005

Wolfsfeld, G., Alimi, E. Y., \& Kailani, W. (2008). News media and peace building in asymmetrical conflicts: The flow of news between Jordan and Israel. Political Studies, 56(2), 374-398. https://doi.org/10.1111/j.1467-9248.2007.00683.x

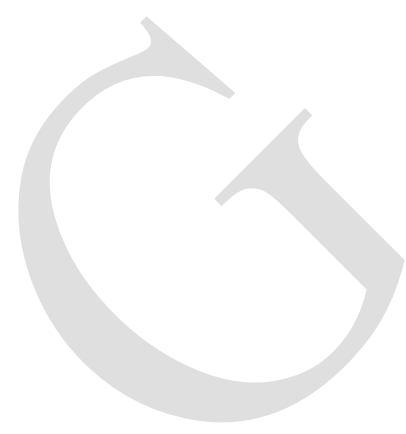

Journal of Humanities, Social and Management Sciences (JHSMS)

25 